\author{
К. В. Базіло, к.т.н., доиент \\ Черкаський державний технологічний університет \\ б-р Шевченка, 460, м. Черкаси, 18006, Україна

\section{ДОСЛІДЖЕННЯ ХАРАКТЕРИСТИК БІМОРФНИХ П’ЄЗОЕЛЕКТРИЧНИХ ПЕРЕТВОРЮВАЧІВ}

У роботі розглянуто технологію додаткових елементів, при якій не потрібна будь-яка доробка п'єзоелемента, а зміна характеристик перетворювача здійснюється за рахунок зовнішніх для п'єзоелемента кіл. Вивчено вплив додаткових індуктивності й ємності на амплітудно-частотні характеристики п'єзоелектричного перетворювача. Досліджено вплив на амплітудно-частотні характеристики п'єзоелектричного перетворювача додаткового опору, підключеного на його вхід і між п'єзоелектричним перетворювачем та загальним проводом. Розглянуто конструкцію та математичну модель біморфного дискового п'єзоелектричного трансформатора з симетричним електричним навантаженням у вторинному електричному колі, що побудована з мінімальною кількістю припущень, які спрощують реальну ситуацію.

Ключові слова: n'єзоелектричний диск, біморфний елемент, технологія проектування, додаткові елементи.

Вступ. Біморфні п’єзокерамічні елементи, в яких збуджуються пружні коливання поперечного вигину, застосовують для вирішення досить широкого кола наукових і технічних задач [1-3].

У роботі [4] описано методи синтезу п’єзоелектричних перетворювачів. Ці методи дають змогу не тільки розширити можливості технології проектування, але й створювати перетворювачі з необхідними характеристиками.

Серед описаних методів особливий інтерес становить технологія додаткових елементів, тому що в цьому випадку не потрібна будь-яка доробка п'єзоелемента, а зміна характеристик перетворювача здійснюється за рахунок зовнішніх для п’єзоелемента кіл.

Суть цієї технології полягає в тому, що до п'єзоелемента приєднують додаткові елементи, які змінюють характеристики перетворювача. До п’єзоелемента механічно приєднують другий п'єзоелемент, металеву пластину або ультразвуковий концентратор, або електричними зв'язками приєднують ємність, індуктивність чи опір [4].

Основною метою статті $є$ дослідження характеристик біморфного п'єзоелектричного елемента.

Матеріали і методи. Розглянемо конструкцію дискового п'єзоелектричного трансформатора, розрахункову схему якого зображено на рисунку 1.

На рисунку 1 позицією 1 показано нерухому опору, позицією 2 - металевий диск, позицією 3 - два однакові п'єзокерамічні диски. Поверхні дисків, які знаходяться в механічному контакті з металевим диском, повністю електродовані і приклеєні високомолекулярним струмопровідним клеєм до металевої круглої пластини. Металева пластина заземлена. На зовнішніх поверхнях п'єзокерамічних дисків розташовуються два кільцеві електроди. На рисунку 1, 6 зображено вид зверху на дисковий біморфний п'єзоелектричний трансформатор. Позицією 4 на рисунку 1 , $\sigma$ показано кільцевий електрод первинного електричного кола. Точно такий же електрод $є$ на зовнішній поверхні нижнього п’єзокерамічного диска. На цю пару кільцевих електродів подається різниця електричних потенціалів від джерела електричних сигналів 3 вихідним електричним опором $Z_{1}$.

Напрямки електричної поляризації п'єзокерамічних дисків зображено на рисунку $1, a$ жирними стрілками. При такому механічному поєднанні п'єзокерамічних дисків електричний потенціал $U_{0} e^{i \omega t}$ на парі кільцевих електродів первинного електричного кола створює, завдяки зворотному п'єзоелектричному ефекту, що змінюється в часі за законом $e^{i \omega t}$, згинальні моменти в області номер 4 (рисунок $1, a$ ), тобто в кільці $R_{3} \leq \rho \leq R_{4}$. Під дією цих згинальних моментів вся конструкція починає здійснювати вісесиметричні коливання поперечного вигину. Деформації, що виникають при цьому, фор-

(С) К. В. Базіло, 2019

DOI: 10.24025/2306-4412.2.2019.166332 
мують в об'ємі п’єзокерамічних дисків змінну в часі за законом $e^{i \omega t}$ електричну поляризацію. На кільцевих електродах вторинного електричного кола дискового п'єзоелектричного трансформатора (позиція 5 на рисунку 1, б) виникають електричні заряди, які своїм електричним полем змушують рухатися вільні носії електрики в провідниках, що з'єднують електричні навантаження (символи $Z_{2}^{( \pm)}$на рисунку $1, a$ ) 3 електродами вторинного електричного кола. В результаті проходження електричного струму на електричних навантаженнях $Z_{2}^{( \pm)}$формуються електричні потенціали $U_{2}^{( \pm)} e^{\text {iөt }}$, які $\epsilon$ вихідними електричними сигналами розглянутого функціонального елемента п'єзоелектроніки.

На рисунку 1, $a$ цифрами 1, 2, 3 і 4 пронумеровано різні за своїми фізичними властивостями області п'єзокерамічних дисків. В областях непарних номерів $n=1 ; 3$ відсутне електродне покриття на зовнішніх поверхнях дисків (область № 1: $\mathrm{R} \leq \mathrm{R}_{1}$, область № 3: $\left.\mathrm{R} \in\left(\mathrm{R}_{2} ; \mathrm{R}_{3}\right]\right)$. В областях парних номерів $\mathrm{m}=2 ; 4$ зовнішні поверхні дисків мають електродне покриття (область № 2: $\mathrm{R} \in\left(\mathrm{R}_{1} ; \mathrm{R}_{2}\right]$, область № 4: $\left.\mathrm{R} \in\left(\mathrm{R}_{3} ; \mathrm{R}_{4}\right]\right)$. Область № 5 це кільце металевої пластини $\mathrm{R}_{4} \leq \mathrm{R}$ (рисунок $1, a$ ).

У загальному випадку можлива ситуація, коли $Z_{2}^{(+)} \neq Z_{2}^{(-)}$. Внаслідок цього амплітудні значення вихідних потенціалів $U_{2}^{(+)} \neq U_{2}^{(-)}$. Це змушує визначити математичну модель дискового біморфного п'єзоелектричного трансформатора в такий спосіб:

$$
K^{( \pm)}=\frac{U_{2}^{( \pm)}}{U_{1}} .
$$

В роботі [5] наведено розрахунки математичної моделі біморфного дискового п’єзоелектричного трансформатора 3 симетричним електричним навантаженням у вторинному електричному колі, яка може бути записана як

$$
K^{(+)}(\omega, \Pi)=\frac{K_{0}^{(2)}\left(\omega, \Pi_{2}\right)}{1+2 i \omega C_{4}^{\sigma} Z_{1}\left[\Psi_{40}\left(\lambda_{2}, \Gamma_{4}\right)+1\right]},
$$

де $\omega$ - колова частота; символом $\Pi_{2}$ позначено набір геометричних, фізико-механічних та електричних параметрів області № 2 біморфного п'єзоелектричного трансформатора; сим-

(C) К. В. Базіло, 2019

DOI: 10.24025/2306-4412.2.2019.166332 вол $\Gamma_{4}$ позначає набір геометричних параметрів області № 4; $\mathrm{C}_{4}^{\sigma}=\pi\left(\mathrm{R}_{4}^{2}-\mathrm{R}_{3}^{2}\right) \chi_{33}^{\sigma} / \alpha$ - динамічна електрична ємність кільцевого об'єму верхнього п’єзокерамічного диска п'єзоелектричного трансформатора; $\chi_{33}^{\sigma}-$ діелектрична проникність; $\alpha$ - товщина диска; $Z_{1}$ - відмінний від нуля комплексний вихідний опір джерела електричного потенціалу; $\lambda_{2}-$ хвильове число; $\mathrm{K}_{0}^{(2)}\left(\omega, \Pi_{2}\right)-$ коефіцієнт електроакустичного зв'язку; символом $\Psi_{40}\left(\lambda_{2}, \Gamma_{4}\right)$ позначено аналітичну конструкцію. При цьому розглядалися тонкі круглі пластини, товщина яких на порядок менша їх діаметра [5].

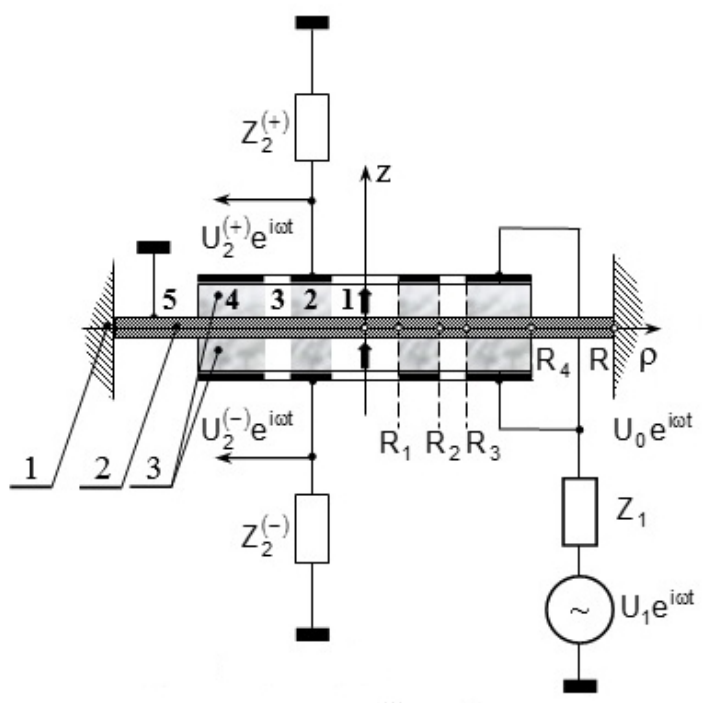

a)

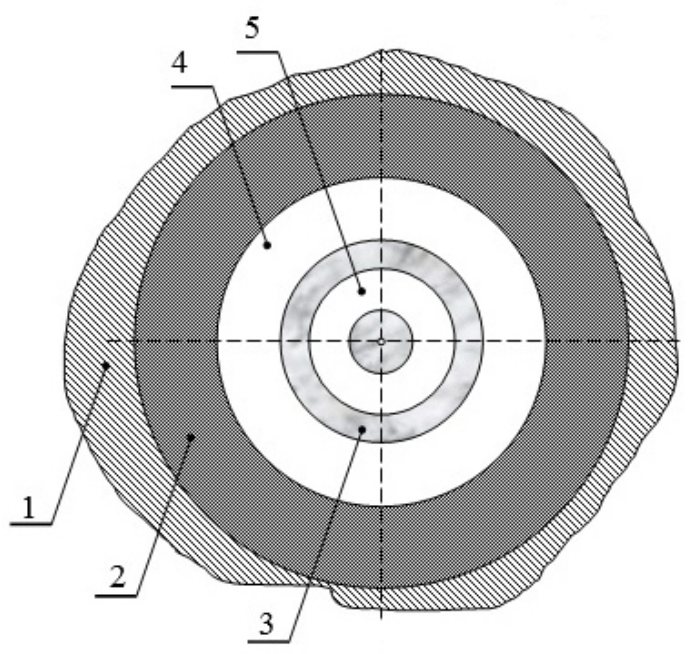

б)

Рисунок 1 - Розрахункова схема біморфного дискового п'єзоелектричного трансформатора 
Експериментальні дослідження. Для експериментальних досліджень було використано електроакустичний перетворювач ЗП-19. Перетворювач складається з пластини зі сталі $40 \mathrm{X}$ діаметром 32 мм і товщиною 0,15 мм. До пластини приклеєний епоксидним компаундом п'єзоелемент Ø23 мм і товщиною 0,2 мм. Біморфний елемент закріплений у корпусі 3 ударостійкого полістиролу (рисунок 2).

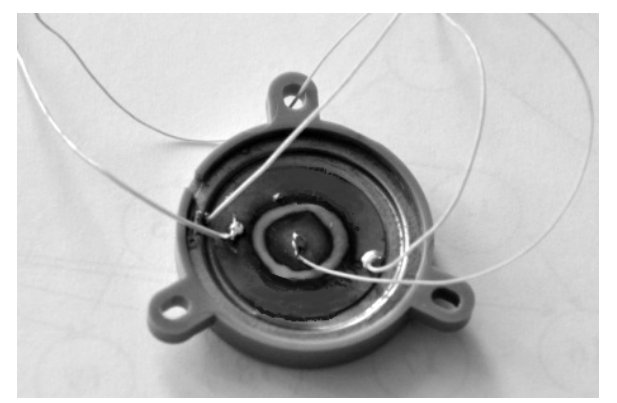

\section{Рисунок 2 - Електроакустичний} перетворювач 3П-19

На вхід п'єзоелектричного трансформатора (ПТ) подавалася напруга від генератора Г3-109. Напруга на виході вимірювалася за допомогою мілівольтметра В3-38 (рисунок $3, a)$. Вимірювалася амплітудночастотна характеристика п’єзоелектричного перетворювача (рисунок 3,6 ).
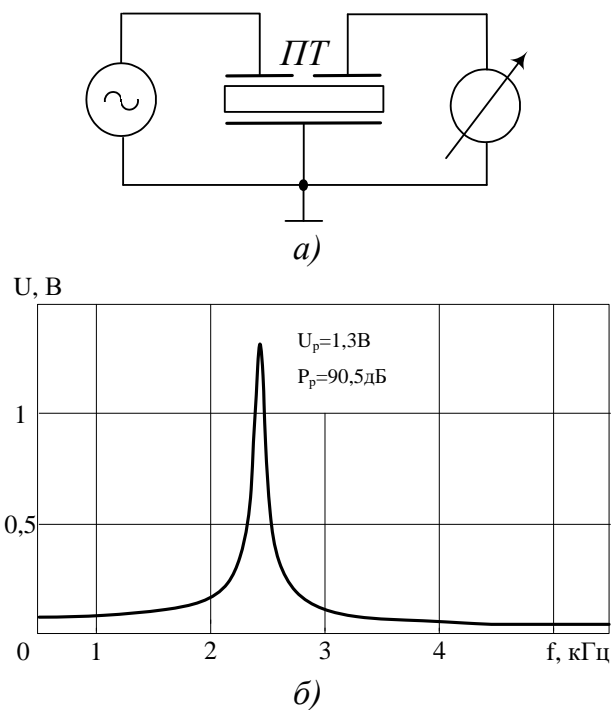

Рисунок 3 - Схема підключення п'єзоелектричного трансформатора $(a)$ i його амплітудно-частотна характеристика (б)

Якщо на вхід п’єзоелемента підключити

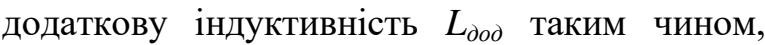
щоб ця індуктивність і міжелектродна ємність
$C_{e л}$ утворили послідовний коливальний контур, характеристики п'єзоелемента зміняться [6, 7].

На рисунку 4, $a$ зображено п’єзоелектричний перетворювач у вигляді п'єзотрансформатора 3 додатковою індуктивністю, причому індуктивність $L 1$ разом із вхідною міжелектродною ємністю п’єзоелектричного перетворювача утворюють коливальний контур. Крім того, індуктивність підбирається таким чином, щоб резонансна частота утвореного коливального контуру збігалася 3 резонансною частотою механічних коливань п’єзотрансформатора [7].

Результати вимірювань показано на рисунку $4, \sigma$.

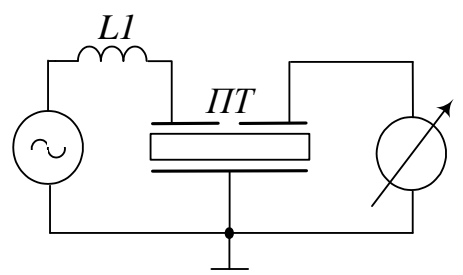

a)

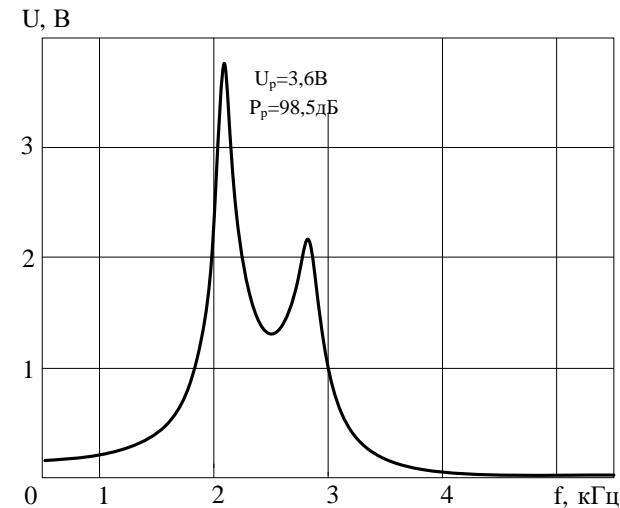

б)

Рисунок 4 - П'єзоелектричний перетворювач з додатковою індуктивністю $(a)$ і його амплітудно-частотна характеристика (б)

3 рисунка 4 видно, що для перетворювача 3 додатковою індуктивністю вдалося підвищити вихідну напругу з 1,3 до $3,6 \mathrm{~B}$, а також збільшити рівень звукового тиску з 90,5 до 98,5 дБ відносно перетворювача без додаткових елементів (рисунок 3) [8].

Міжелектродні ємності п’єзоелемента вимірювалися за допомогою цифрового мультиметра Voice kraft M890G. На вхід п'єзоелемента подавався синусоїдальний сигнал амплітудою 1 В. Для вимірювань амплітудно-частотної характеристики (АЧХ) використовувалися генератор Г3-109 і мілівольтметр B3-41. 
Цікавим є вивчення впливу додаткової ємності, яка підключається до п’єзоелемента одночасно $з$ додатковою індуктивністю.

Для випадку, коли додаткова індуктивність підключається на вхід п’єзоелемента, варіанти підключення додаткової ємності зображено на рисунку 5.

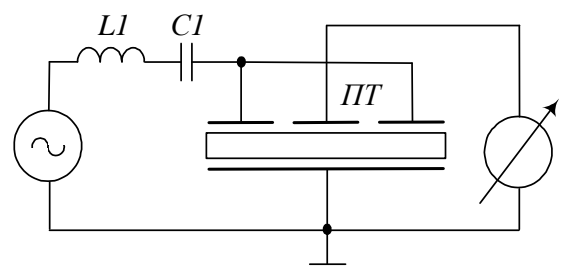

a)

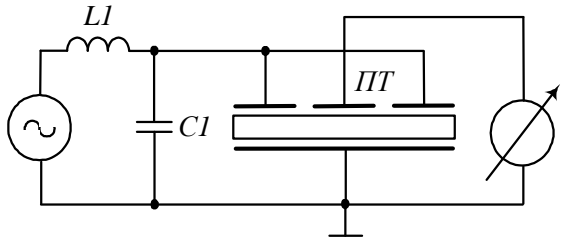

б)

Рисунок 5 - П'єзоелектричний перетворювач з додатковими індуктивністю і смністю

У першому варіанті (рисунок 5, $a$ ) додаткова ємність C1 підключається послідовно L1. При послідовному з’єднанні C1 і вхідної міжелектродної ємності п’єзоелемента $C_{B x}$ сумарна ємність зменшується, тому слід очікувати зсуву резонансних частот в область високих частот. Це видно 3 наведених АЧХ для цього варіанта (рисунок 6).

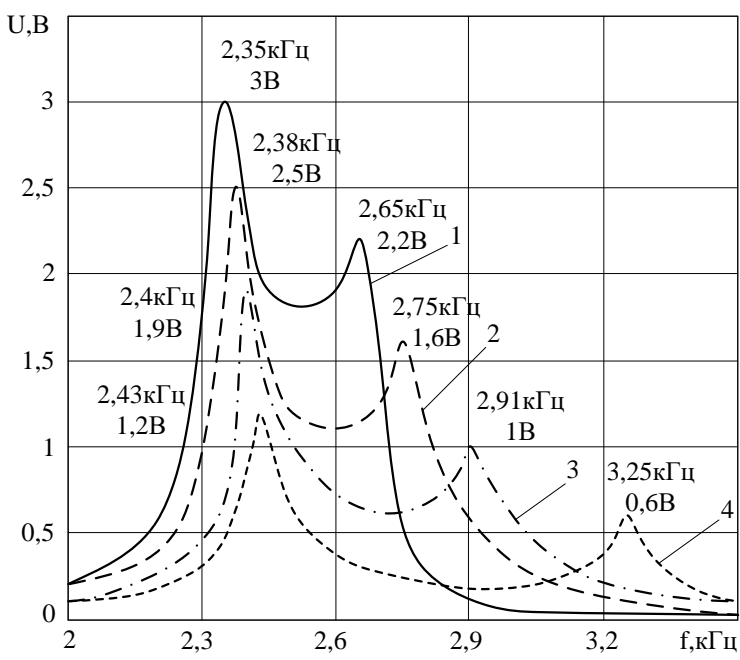

Рисунок 6 - Амплітудно-частотні характеристики п’єзоелектричного перетворювача згідно 3 рисунком 5 , $a$ при $L 1=$ const, $1-C=60 \mu \Phi, 2-C=33 н \Phi$, $3-C=22 \mu \Phi, 4-C=14 н \Phi$
У другому випадку (рисунок 5, б) утворюється коливальний контур $L 1\left(C 1+C_{B x}\right)$, що призводить до зсуву резонансної частоти в область низьких частот (рисунок 7) [9].

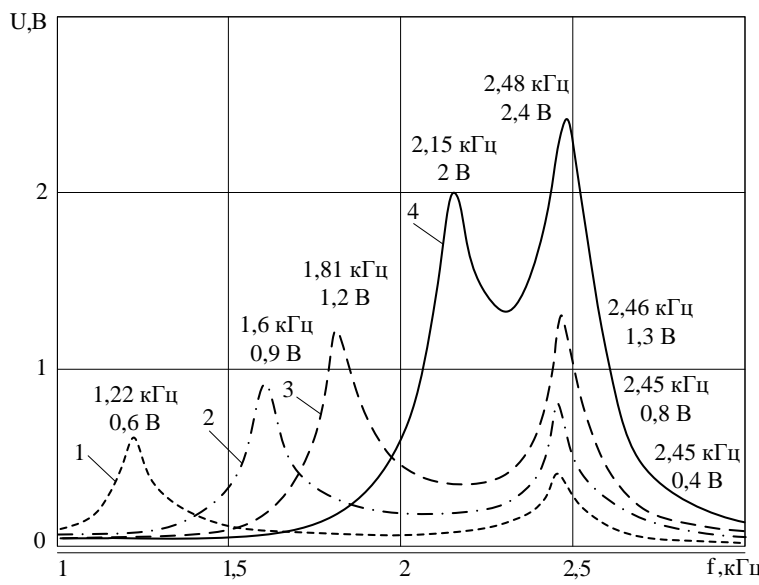

Рисунок 7 - Амплітудно-частотні характеристики п'сзоелектричного перетворювача згідно з рисунком 5, б при $L 1=$ const, $1-C=33 н \Phi, 2-C=14 \mu \Phi$, $3-C=7 \mu \Phi, 4-C=1 \mu \Phi$

Для розширення робочого діапазону п’єзоелементи можуть включатися в схеми електричних фільтрів. Найчастіше в цих випадках використовуються схеми фільтрів нижніх і верхніх частот.

На рисунку 8 зображено схему підключення додаткового опору на вхід п’єзоелектричного перетворювача [10], а на рисунку 9 - пї амплітудно-частотні характеристики.

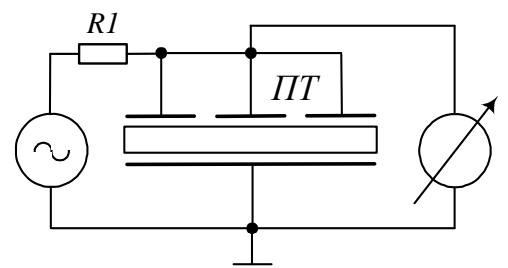

\section{Рисунок 8 - Схема підключення додаткового опору $R 1$ на вхід перетворювача}

На рисунку 10 зображено схему підключення додаткового опору між п’єзоелектричним перетворювачем і загальним проводом [10], а на рисунку 11 - iї амплітудно-частотні характеристики. 


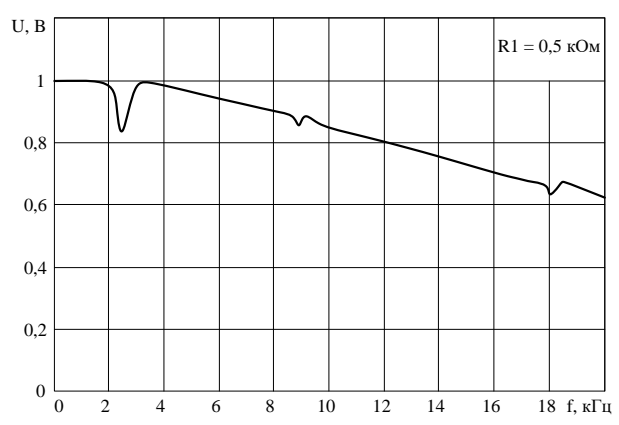

a)

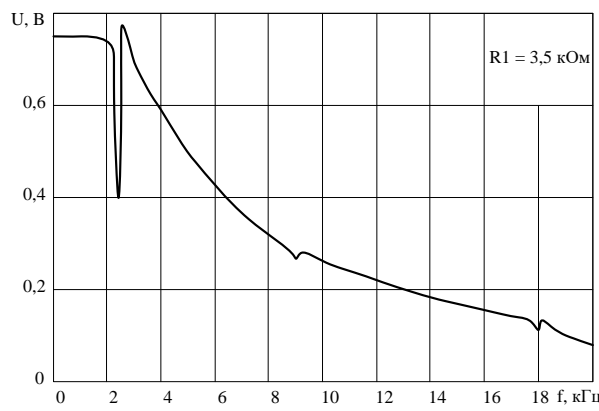

б)

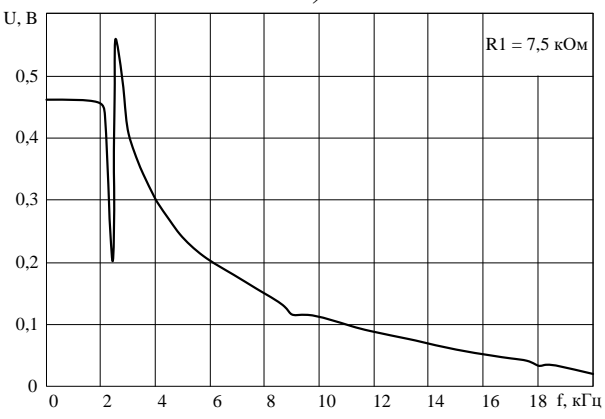

в)

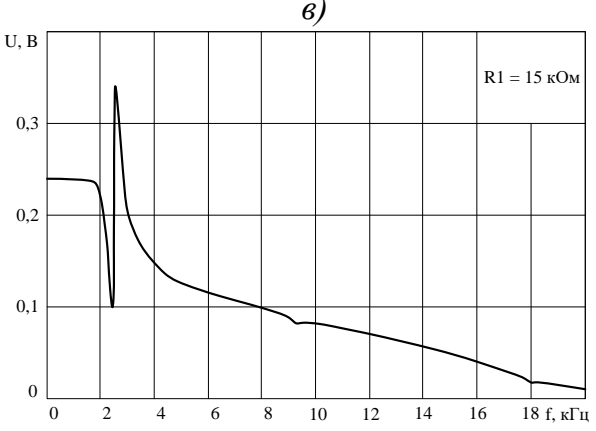

2)

a) 0,5 кОм; б) 3,5 кОм; в) 7,5 кОм; г) 15 кОм

Рисунок 9 - Амплітудно-частотна характеристика п'сзоелектричного перетворювача

3 додатковим опором $R 1$ згідно з рисунком 8

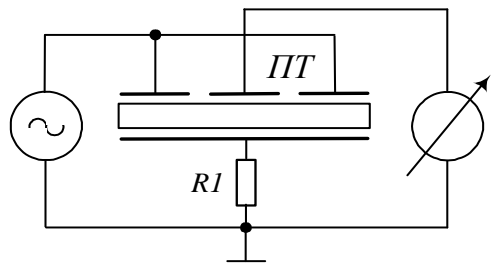

Рисунок 10 - Схема підключення додаткового опору $R 1$ на вхід перетворювача

(с) К. В. Базіло, 2019

DOI: 10.24025/2306-4412.2.2019.166332

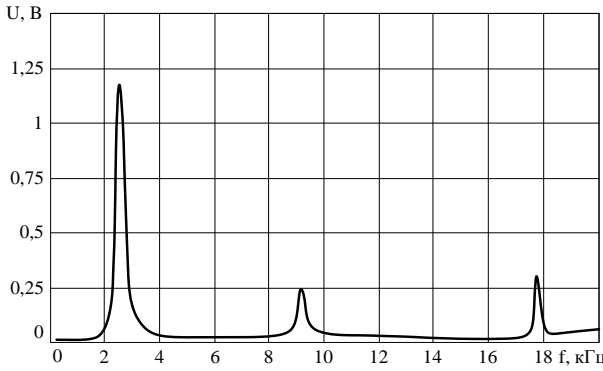

a)

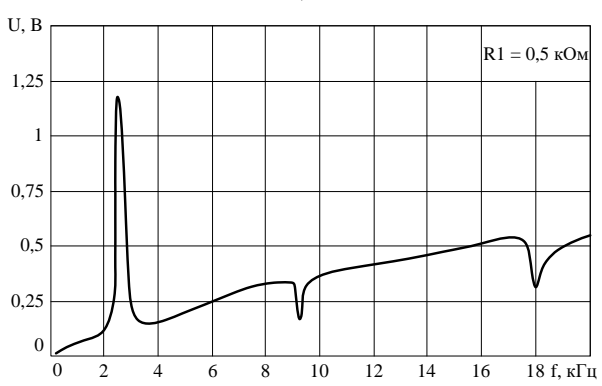

б)

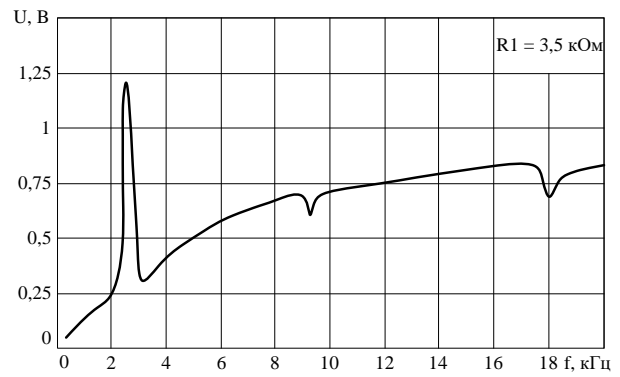

в)

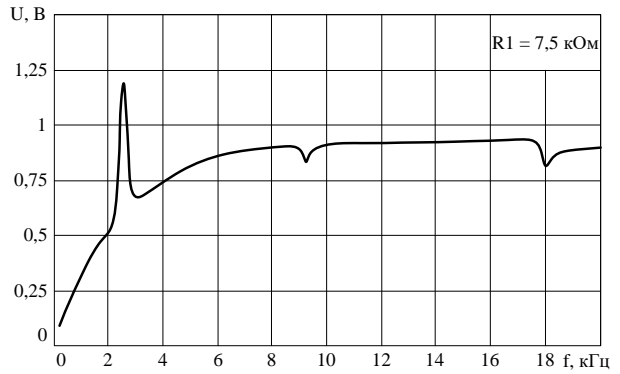

2)

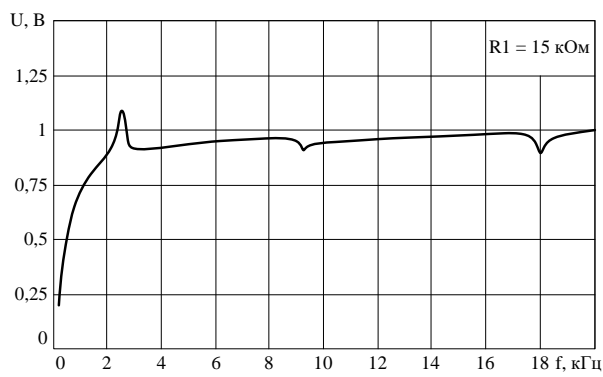

d)

a) 0 кОм; б) 0,5 кОм; в) 3,5 кОм;

г) 7,5 кОм; д) 15 кОм

Рисунок 11 - Амплітудно-частотна

характеристика п'єзоелектричного перетворювача 3 додатковим опором $R 1$ згідно з рисунком 10 
Як видно з рисунків 9, 11, підключення додаткового опору на вхід п'єзоелектричного перетворювача або між п’єзоелектричним перетворювачем і загальним проводом, тобто створення схем фільтрів нижніх або верхніх частот на основі п'єзоелектричного перетворювача, дає змогу керувати полосою частот пропускання перетворювача.

Висновки. Основний результат статті можна зафіксувати в такий спосіб: розглянуто технологію додаткових елементів; вивчено вплив додаткових індуктивності й ємності на амплітудно-частотні характеристики п'єзоелектричного перетворювача; досліджено вплив на амплітудно-частотні характеристики п'єзоелектричного перетворювача додаткового опору, підключеного на його вхід та між п'єзоелектричним перетворювачем і загальним проводом.

\section{Список літератури}

[1] V. Sharapov, Piezoceramic sensors. Springer, 2011.

[2] Р. Г. Джагупов и А. А. Ерофеев, Пьезоэлектронные устройства вычислительной техники, систем контроля и управления. Санкт-Петербург: Политехника, 1994.

[3] О. Н. Петрищев, "Гармонические колебания пьезокерамических элементов в вакууме и метод резонанса - антирезонанса" (часть 1) в Гармонические колебания пьезокерамических элементов. Киев: Аверс, 2012.

[4] В. М. Шарапов, "Технологии синтеза пьезокерамических датчиков", Вісник Черкаського державного технологічного університету, № 3, 2010 (Технічні науки).

[5] О. Н. Петрищев, и К. В. Базило, Принциипы и методы математического моделирования колеблющихся пьезоэлектрических элементов. Черкассы: ЧП Гордиенко, 2019.

[6] В. М. Шарапов, "Спосіб створення акустичних коливань за допомогою п'єзоелемента", 56930 Україна, МПК H04R 17/00. № 201012462, Янв. 25, 2011.

[7] В. М. Шарапов, та ін. "Електроакустичний перетворювач", 56932 Україна, МПК H04R 17/00. № 201012464; Янв. 25, 2011.

[8] В. М. Шарапов, К. В. Базило, Ж. В. Сотула, и В. Е. Снитюк, "Исследование пьезоэлектрических преобразователей с доба- вочными колебательными контурами", Вісник Черкаського державного технологічного університету, № 1, с. 35-38, 2013 (Технічні науки).

[9] В. М. Шарапов, К. В. Базило, Ж. В. Сотула, А. С. Ткаченко, и др., "Методы синтеза пьезоэлектрических преобразователей: метод добавочных элементов. Индуктивность + емкость", Вісник Черкаського державного технологічного університеmy, № 2, с. 59-62, 2011 (Технічні науки).

[10] В. М. Шарапов, В. В. Туз, К. В. Базило, и А. С. Ткаченко, "Схемотехническое моделирование пьезоэлектрических преобразователей с добавочным сопротивлением", Вісник Черкаського державного технологічного університету, № 3, с. 74-76, 2011 (Технічні науки).

\section{References}

[1] V. Sharapov, Piezoceramic sensors. Springer, 2011.

[2] R. G. Dzhagupov, and A. A. Erofeev, Piezoelectronic devices of computing equipment, control and monitoring systems. St. Petersburg: Politehnika, 1994 [in Russian].

[3] O. N. Petrishchev, Part 1. "Harmonic vibrations of piezoceramic elements in vacuum and a method of resonance - antiresonance" (part 1) in Harmonic oscillations of piezoceramic elements. Kiev: Avers, 2012 [in Russian].

[4] V. M. Sharapov, "Technologies of synthesis of piezoceramic sensors", Visnyk Cherkaskogo derzhavnogo tehnologichnogo universytetu, no. 3, 2010 [in Russian].

[5] O. N. Petrishchev, and C. V. Bazilo, Principles and methods of mathematical modelling of oscillating piezoelectric elements. Cherkasy: Gordienko, 2019 [in Russian].

[6] V. M. Sharapov, "A method of creating acoustic oscillations using a piezoelectric element", Patent of Ukraine 56930, Jan. 25, 2011 [in Ukrainian].

[7] V. M. Sharapov, et al. "Electroacoustic transducer", Patent of Ukraine 56932, Jan. 25, 2011 [in Ukrainian].

[8] V. M. Sharapov, C. V. Bazilo, Zh. V. Sotula, andV. E. Snityuk, "Investigation of piezoelectric transducers with additional oscillatory circuits", Visnyk Cherkaskogo derzhavnogo tehnologichnogo universytetu, no. 1, pp. 35-38, 2013 [in Russian]. 
[9] V. M. Sharapov, C. V. Bazilo, Zh. V. Sotula, A. S. Tkachenko, et al., "Methods of synthesis of piezoelectric transducers: the method of additional elements. Inductance + capacitance", Visnyk Cherkaskogo derzhavnogo tehnologichnogo universytetu, no. 2, pp. 5962, 2011 [in Russian].
[10] V. M. Sharapov, V. V. Tuz, C. V. Bazilo, and A. S. Tkachenko, "Circuit simulation of piezoelectric transducers with additional resistance", Visnyk Cherkaskogo derzhavnogo tehnologichnogo universytetu, no. 3, pp. 7476, 2011 [in Russian].

\section{V. Bazilo, Ph.D. (Eng.), associate professor Cherkasy State Technological University \\ Shevchenko blvd, 460, Cherkasy, 18006, Ukraine \\ INVESTIGATION OF CHARACTERISTICS OF BIMORPH PIEZOELECTRIC TRANSDUCERS}

Bimorph piezoceramic elements, in which elastic oscillations of transverse bending are excited, are used to solve a wide range of scientific and technical problems. The relevance of the use of various functional elements of piezoelectronics in power and informational systems is explained, first of all, by their high reliability, as well as small dimensions and weight, which greatly facilitates the solution of the problem of miniaturization of such systems. The technologies and devices that use the direct and / or reverse piezoelectric effect in the principles of their work are promising. The purpose of this article is to study the characteristics of a bimorph piezoelectric element.

The main result of this article can be fixed as follows: the paper considers the technology of additional elements, which does not require any refinement of the piezoelement, and the change in the characteristics of the transducer is carried out due to the external circuits for the piezoelement. The influence of additional inductance and capacitance on the amplitude-frequency characteristics of the piezoelectric transducer is studied. The influence of additional resistance connected to piezoelectric transducer's input on its amplitude-frequency characteristics is investigated. Manipulating the additional elements, you can have a significant effect on the energy of oscillatory motion of material particles of piezoelectric disk volume. The construction and mathematical model of a bimorph disk piezoelectric transformer with a symmetric electric load in a secondary electric circuit, constructed with a minimal number of assumptions, which simplify the real situation, are considered. In addition, using a mathematical model, the sensitivity of the characteristics of piezoelectric transformer to variations in the parameters of its design elements is easily determined. Having these dependencies, it is possible to make a rational choice of the technology for manufacturing a product. Thus, a qualitative mathematical model can significantly reduce the time and cost of developing new models of piezoelectric transformers.

Keywords: piezoelectric disk, bimorph element, design technology, additional elements.

Стаття надійшла 08.05.2019

Прийнято 24.05.2019 